\title{
Surgical extraction of an unusual macrocystic lymphatic malformation in the buttock: case report
}

Francisco Antonio Rodríguez-García', Cuauhtly Gallegos-Sierra', José Luis Villarreal-Salgado ', Karla Jimenez-Pavon ', Karen Morfin-Meza', Joel Ramos-Maciel', Diego Armando Fierro-Rodríguez', Enrique Romero-Algara', Pablo Bonilla-Catalán ${ }^{1}$, Emmanuel Dorado-Hernández ${ }^{1}$ and Quitzia Libertad Torres-Salazar ${ }^{2^{*}}$ (D)

\begin{abstract}
Background: Macrocystic lymphatic malformation is a rare benign skin disorder, especially the anogenital area, which covers less than .5\% of the reported cases. It can cause vesicular and papular lesions on the face, trunk, extremities, and, less frequently, anogenital areas. Although there are currently several therapeutic options, surgical excision is the most widely used, considering the lowest recurrence rate.

Case presentation: In this article, we describe the case of a 15-year-old male patient who presented with herpetiform skin lesions, corresponding to the diagnosis of macrocystic lymphatic malformation, in the lower region of the right buttock. After confirmation of the diagnosis by histopathology, surgical excision was performed with a tensor fascia lata graft, with successful aesthetic and functional results.

Conclusions: Considering the diagnosis of macrocystic lymphatic malformation is of utmost importance, although its presence is unusual, to differentiate it from other herpetiform lesions. Despite the existence of multiple approaches today, definitive treatment with surgical extraction is necessary, both to improve the cosmetic aspect and to prevent associated complications. It is suggested that histopathological and imaging diagnostic tools be used as a routine element, in order to increase therapeutic success, as well as decrease the risk of recurrences.
\end{abstract}

Evidence-based medicine ranking: Level IV

Keywords: Lymphangioma, Lymphangioma circumscriptum, Macrocystic lymphatic malformation surgery, Case report

\section{Background}

Lymphatic malformations are low-flow vascular abnormalities of the lymphatic system, occurring in 2.5 to 5 individuals per 100,000 live births [1]. Lymphatic malformations are unusual and benign proliferation, among which 3 types can be distinguished: circumscribed,

\footnotetext{
* Correspondence: quitzia.torres@gmail.com

The authors declare that the present study did not have a subsidy or external support to the hospital to carry it out. We also declare that we have no conflicts of interest.

Corresponding Author: Torres-Salazar QL.

Universidad Juárez del Estado de Durango, Durango, Mexico

Full list of author information is available at the end of the article
}

cavernous, and cystic (as well as mixed forms). Macrocystic lymphatic malformation (MLM) formerly known as lymphangioma circumscriptum (LC) is considered primary (or congenital) if it is present at birth or if it develops in early childhood and secondary (or acquired) if it is caused by altered lymphatic flow [1, 2]. Lymphangiomas are described as rare compared to hemangiomas; however, it is important to think about them in order to make an early diagnosis, as well as to provide the patient with a clear perspective of his or her prognosis, taking into account that there is a high percentage of recurrences after treatment [3]. The goal of treatment is to 
maintain functionality, control associated symptoms, and preserve aesthetic integrity $[4,5]$. Depending on the location and extent of the injury, lymphatic malformations can compromise vital functions. Up to $75 \%$ of lymphatic malformations are found in the cervicofacial region [6], and with reduced frequency, we can find them in the chest/axilla, mediastinum, retroperitoneum, buttocks, and anogenital region [7]. Treatment modalities include observation, surgery, sclerotherapy, and drug treatment [8], and the decision to use any of them must consider risks and benefits. Although the use of sclerotherapy has become popular in recent decades, the first-line treatment for cases where the extent of the lesion and functional limitation is important continues to be surgery. In these cases, complete resection with the appropriate surgical technique will be the most important point for a favorable prognosis $[9,10]$. Our objective is to present the surgical approach performed in a case of macrocystic lymphatic malformation, presented in the right gluteus, this being an unusual region.

\section{Case presentation}

Consider a [11]year-old male patient with no significant medical history. He manifests first clinical data at the age of 9 years, with the appearance of punctate lesions in the epidermis of the right gluteus, presenting bleeding and pain when rubbing. The lesions were managed by the dermatology service using cryosurgery, with apparent success; however, 2 years later, the lesions recurred, presenting a higher growth rate. On this occasion, the lesions presented herpetiform characteristics, with dimensions of $20 \times$ $10 \mathrm{~cm}$ (Fig. 1) and a murmur in the middle third of the lesion, at the linear Doppler signal.

A biopsy of the lesion was taken, with the following histopathological report: hyperkeratotic epidermis with focal acanthosis, dermis with dilated vascular lumens, and eosinophilic material inside suggestive of macrocystic lymphatic malformation [12]. The department of vascular surgery and hemodynamics performed a diagnostic angiography, observing the right hypogastric artery with multiple dependent and collateral branches towards the gluteal region. Subsequently, a magnetic resonance was performed (Figs. 2 and 3), where multiplanar acquisitions are made at the level of the right thigh, in $\mathrm{T} 1$ and T2 sequences with fat suppression, reporting a lesion compatible with lymphatic malformation in the subcutaneous cutaneous plane of the right gluteal region, without data of extension towards deep planes, without evidence of prominent vascular structures or calcifications that suggest phleboliths. The muscular structures were found intact, as well as both femurs and aponeurotic tracts. Finally, the $20 \times 10 \mathrm{~cm}$ lesion was cleavage, with margins of $2 \mathrm{~cm}$ and the vascular bed was ligated.

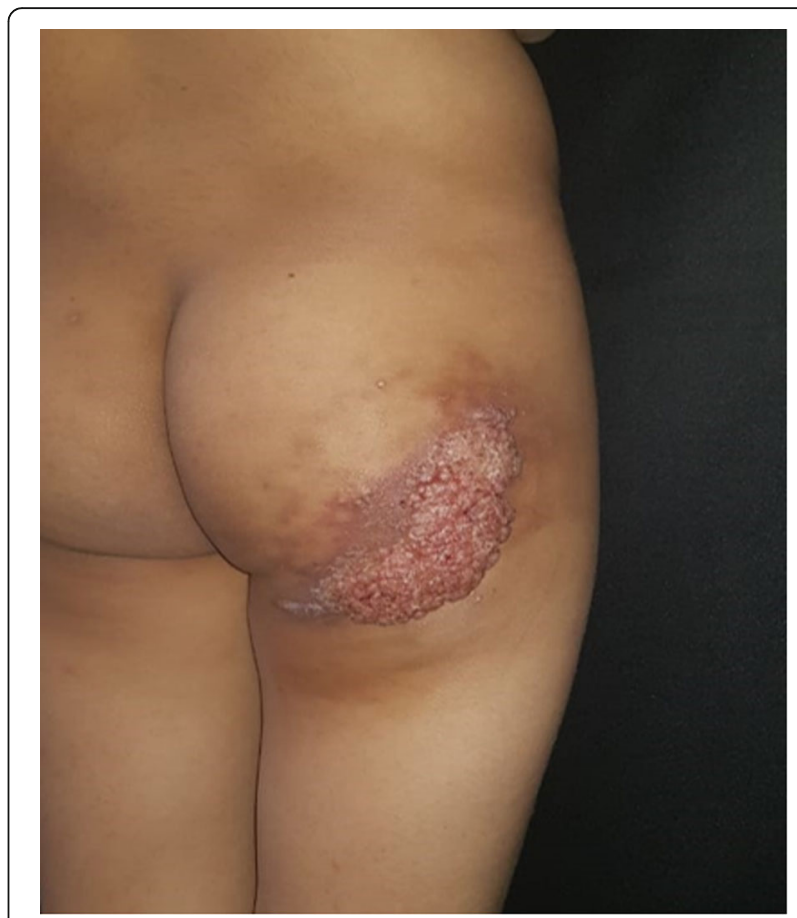

Fig. 1 Macrocystic lymphatic malformation in the right buttock with herpetiform characteristics

A reconstructive method was decided as rotation flap over fascia latae graft right of the defect right buttock.

\section{Surgical technique}

The tensor fascia latae flap is a type I muscle-fasciocutaneous flap, based on the transverse branch of the lateral circumflex femoral artery and its concomitant veins. The muscle is innervated by the superior gluteal

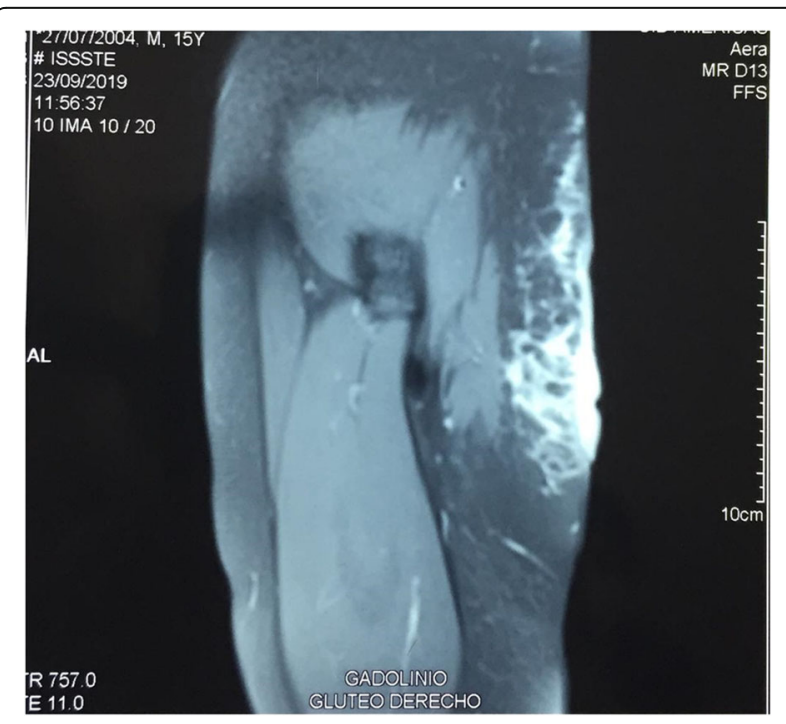

Fig. 2 Right thigh MRI 


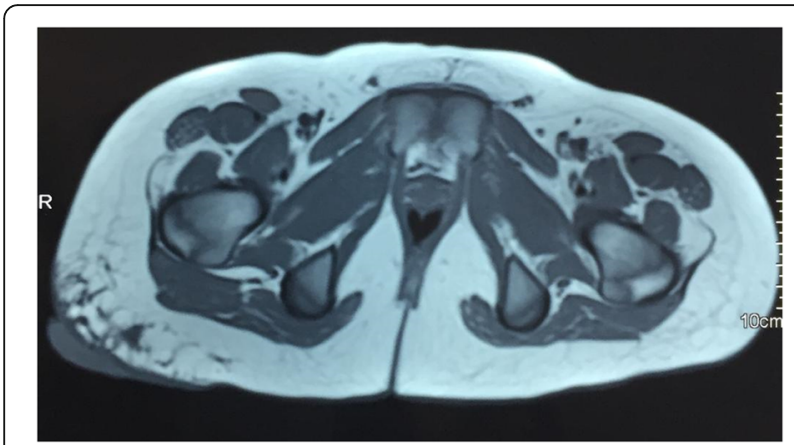

Fig. 3 Magnetic resonance imaging

nerve and the cutaneous territory by branches of T12 in the upper part and the lower part through the lateral femoral cutaneous nerve (L2-3). It is indicated mainly in defects secondary to pressure ulcers at the trochanter and ischial level [13-15].

The anterior superior iliac spine (ASIS) and the anterior border of the lateral femoral condyle were taken as reference points; a line was drawn between these 2 points and this represented the anterior border of the flap (Fig. 4).

The skin graft can be extended 8 to $15 \mathrm{~cm}$ after this line. The distal edge of the skin graft can be located up to $40 \mathrm{~cm}$ below the ASIS. The pedicle is located $10 \mathrm{~cm}$ below the ASIS on the axis between the ASIS and the patella (this point is commonly [15] to $15 \mathrm{~cm}$ lateral to the pubic tubercle). The incision is made at the level of the distal edge, until the fascia which is incised is evident.

The incisions are continued at the medial and lateral levels in a subfascial plane, on the vastus lateralis muscle, and in a superior direction (Fig. 5). At the moment the $10 \mathrm{~cm}$ below the ASIS is reached, it is readily evident of the vascular pedicle in most cases, and it is not necessary to separate the origin of the muscle; however, it is sometimes necessary to realize it for better rotation arc and avoid ears of dog (Figs. 5 and 6). The flap can also be designed as a V-in-Y flap primarily to cover trochanteric defects. The base of the $\mathrm{V}$ is the edge of the debrided ulcer. The flap is designed in a $\mathrm{V}$ shape and the skin, muscle, and fascia are incised. There is a need to release the insertions of the muscle and then proceed to advance and close in a Y-shape, which in the case of our patient was taken and applied graft to avoid excessive tension due to the covered area.

If a functional transfer is required, a branch of the superior gluteal nerve is exposed and dissected between the gluteus medius and gluteus minimus muscles in its proximal portion, on the posterior surface and the deep plane of the hilum. The vascular branches of the pedicle are identified and ligated for

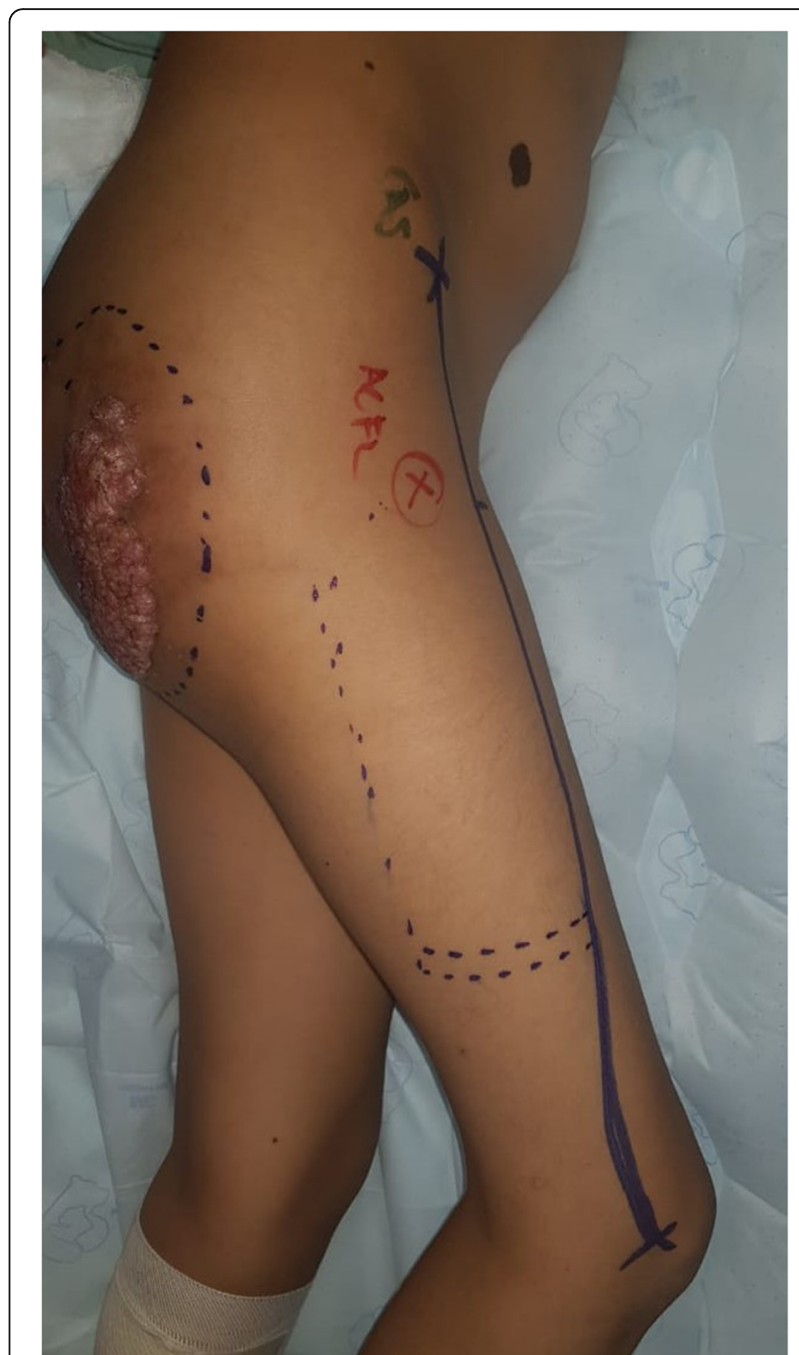

Fig. 4 Reference points

the neighboring muscles, including the gluteus minus and the vastus lateralis (Fig. 7). The tensor fasciae latae (TFL) muscle is separated from the vastus lateralis, rectus femoris, sartorius, and gluteal muscles. The small vascular branches for these muscles must be ligated and care must be taken to preserve the branches of the superior gluteal nerve for the gluteal muscles. Pedicle dissection continues until the desired length is obtained, usually 4-6 cm (after fully releasing the muscle, the lateral circumflex femoral artery can be dissected down to the deep femoral artery for extra length when necessary). After pedicle isolation, the muscle is separated from its origin (ASIS) and the muscle flap is raised supported by its vascular or neurovascular pedicle. To reduce the volume of the flap or reduce the morbidity of the donor area (depression of the contour in the upper lateral region of the thigh), a small portion of the muscle can be obtained according to the requirement of the defect. This can 


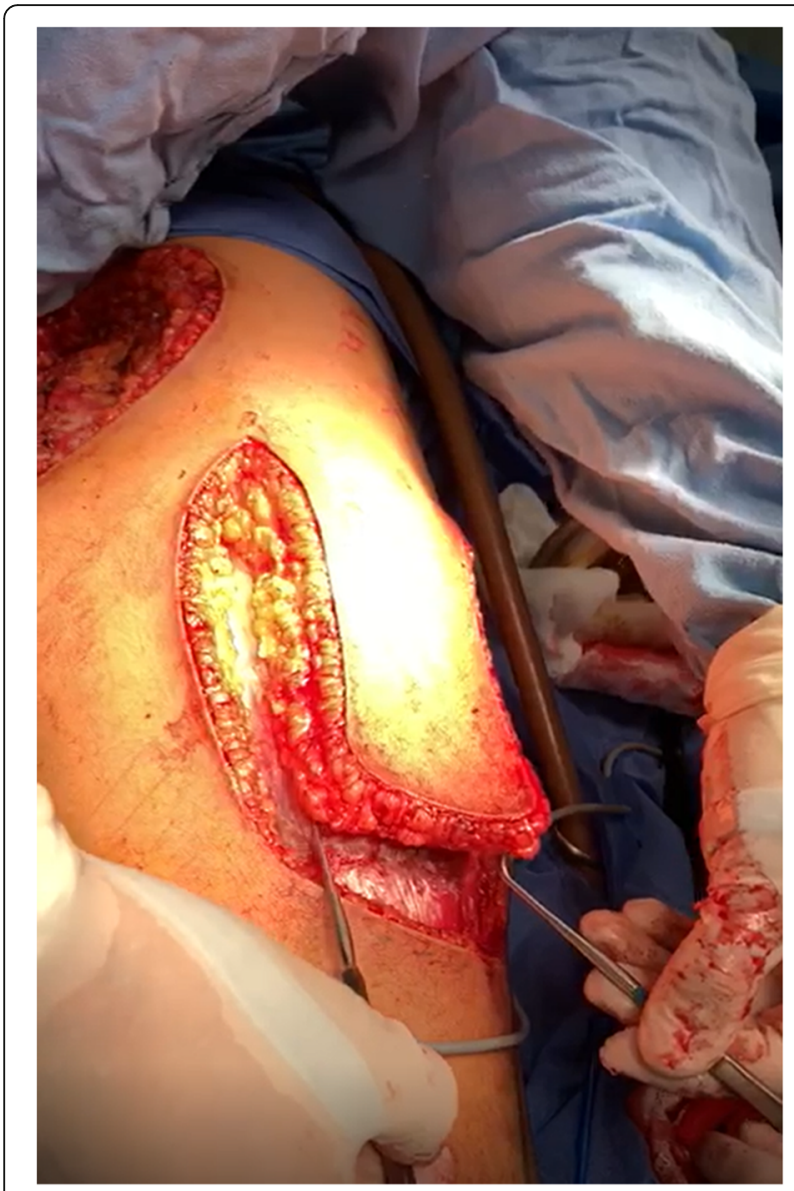

Fig. 5 Middle and lateral incisión

be provided by including only the muscle around the pedicle for the flap (hilum) and below it and preserving the superior, anterior, and posterior portions, even a small piece. The donor area is generally closed by skin grafts (Fig. 8). The postoperative period was uneventful and the patient was discharged from the hospital 10 days after surgery (Fig. 9). Finally, at 10 months, we could see that the flap and the graft were successfully integrated (Fig. 10). The patient showed good post-surgical tolerance, and there were no adverse events or unexpected incidents.

\section{Discussion}

Lymphatic malformation appears more frequently in children under 1 year, slightly diminishing its incidence to 5 years, and gradually decreases to 16 years [15]; coupled with this and its location (lower region of the gluteus), the case presented here is an extremely unusual form of lymphangioma, being more frequent in the head, neck, and armpit. As previously mentioned, LC in the genital or perianal areas are rare and have been reported more commonly in women than in men. Akhavan et al. [11] after an exhaustive review found only 35 cases

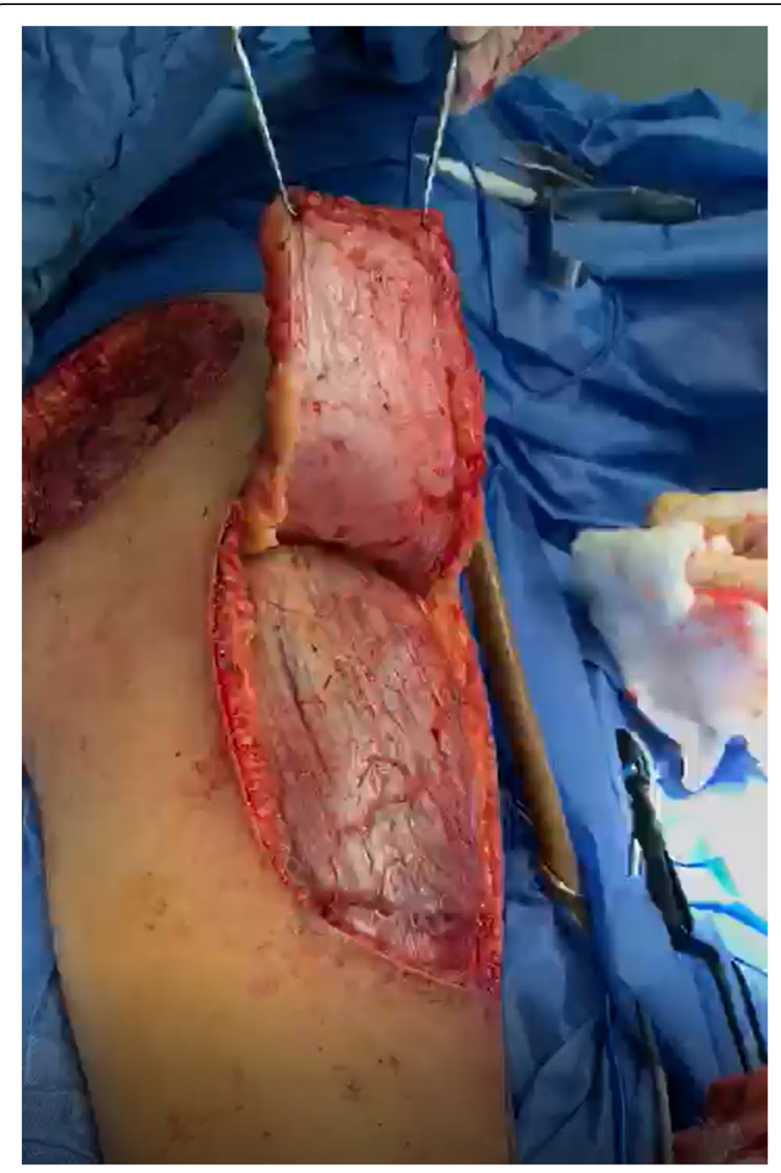

Fig. 6 Proximal dissection of the flap on the vastus lateralis muscle, in the subfascial plane

reported in the literature of vulvar LC and made the report of a 33-year-old patient, who underwent surgical excision. Akhavan and others agree that, in order to make the diagnosis certainty, as well as to decide the therapeutic conduct, we must resort to laboratory and imaging methods such as computed tomography (CT), magnetic resonance (MR), and histopathology, differentiating LC from a possible herpes zoster, molluscum contagiosum, hydrogenitis, liomioma, and genital warts. In our patient, the diagnosis of LC was performed histopathologically.

Currently, there are various treatment modalities, such as radiofrequency ablation, sclerotherapy, ablative lasers, and surgical excision of the superficial and deep components to prevent recurrence of the lesion, which is the most common postoperative complication with a recurrence rate up to $25-50 \%$ in the first 3 months [16]. It is necessary to observe the individual pathological characteristics in order to decide the type of treatment to be used, taking into account the high recurrence rate. Initially, our patient underwent cryosurgery; however, 2 years later, he presented a recurrence with herpetiformis 


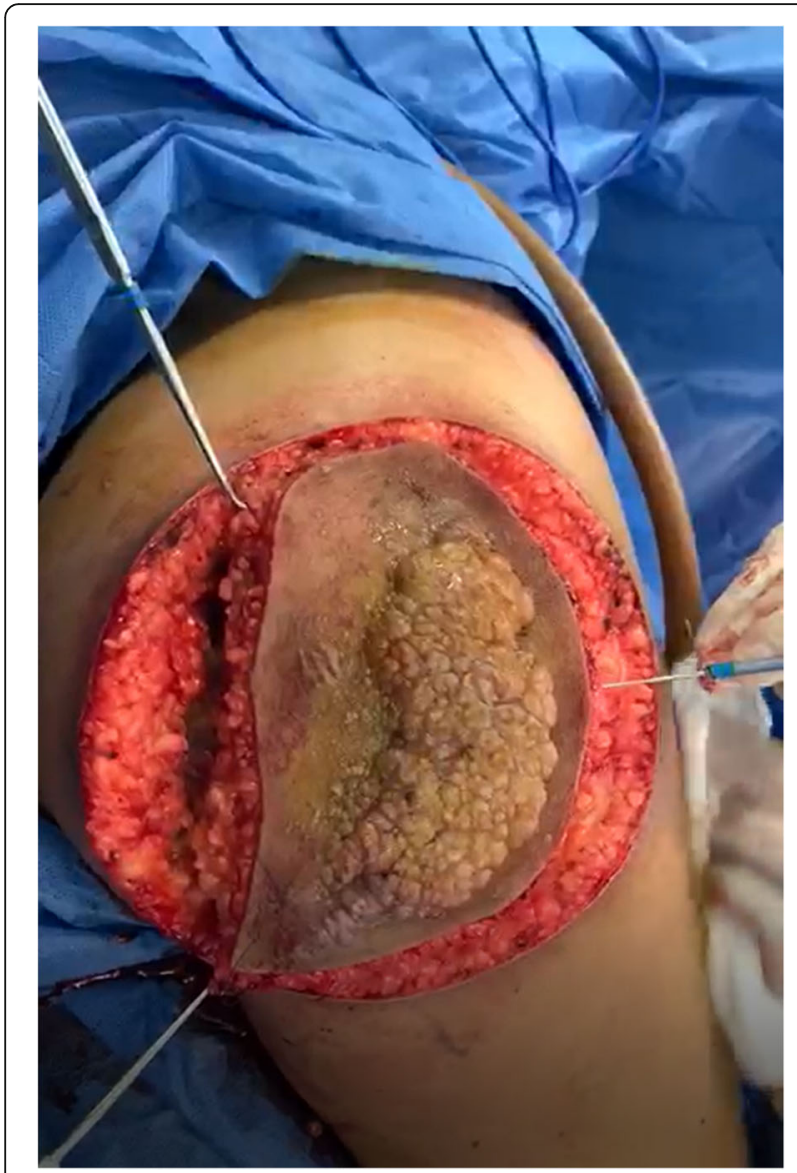

Fig. 7 Gluteal dissection

lesions, which involved a larger tissue area. It has been described that, for cases, such as the one presented here, the surgical modality presents a success rate higher than $75 \%$ [17].

Mosche et al. have reported the successful use of a combination of radiofrequency current and 900-nm diode laser in the treatment of six LC patients [18]. Notwithstanding the decided technique, the main objective of the treatment must always be to eliminate or destroy

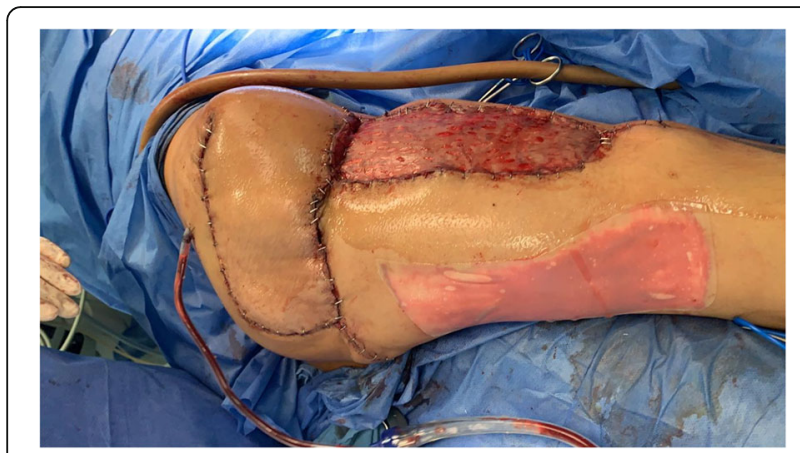

Fig. 8 Y-graft, closure of the donor area with adjacent skin tissue

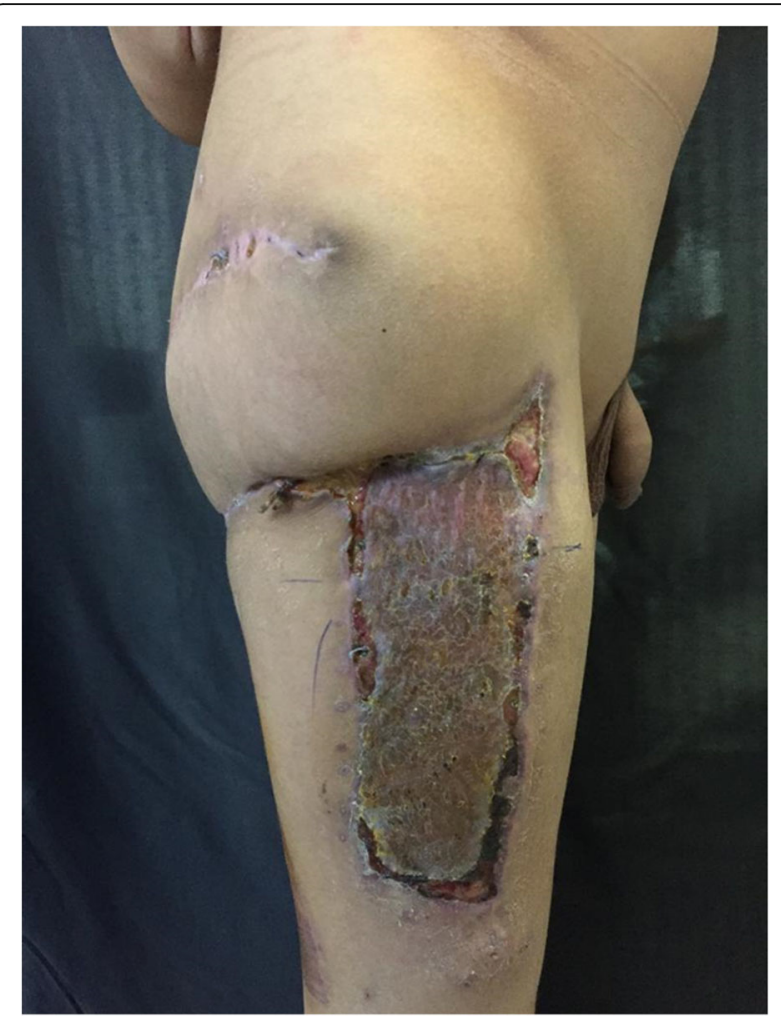

Fig. 9 Image of the patient after 14 days of recovery. Right thigh

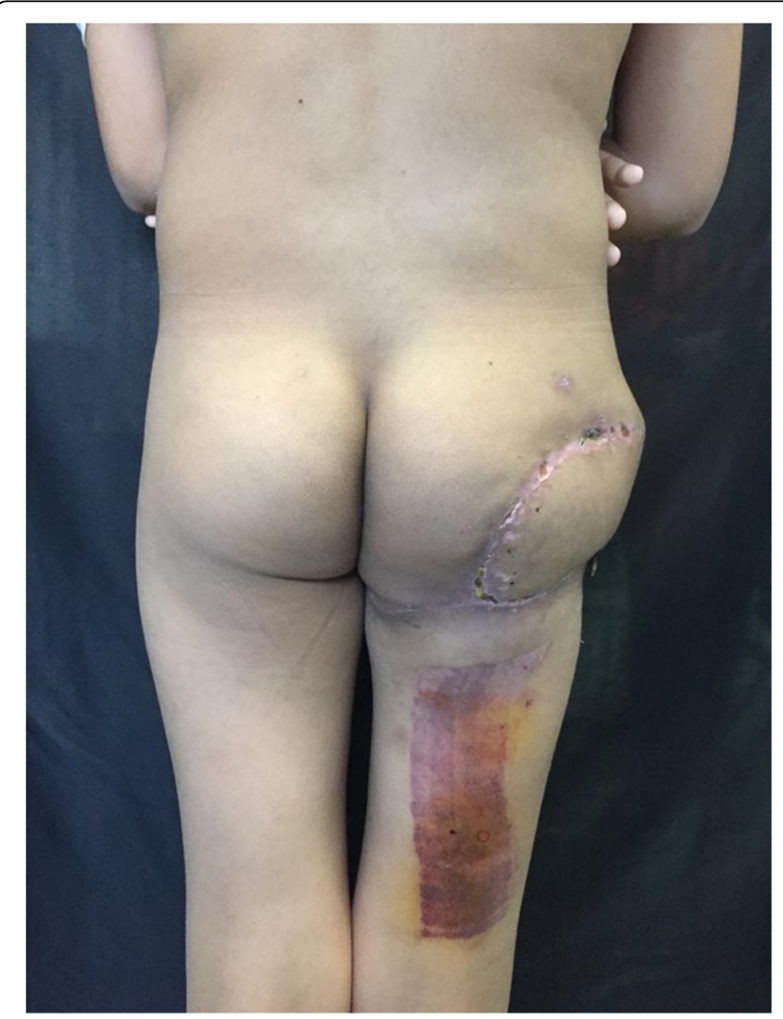

Fig. 10 Image of the patient at 14 days of recovery. Right gluteus 
the diseased lymphatic and subcutaneous components that serve as a nest for recurrence.

The TFL muscle was first used by Wangensteen in 1934 as a pedunculated flap without overlying skin to repair large hernial defects. The TFL muscle has a single dominant pedicle (Mathes and Nahai type I muscle) that sends musculocutaneous perforators to irrigate the overlying skin. In large defects, as was the case in our patient, functional reconstruction can be achieved with vascularized thigh tissue. It has been demonstrated that there are no significant functional or aesthetic sequelae in the donor areas, even when fasciocutaneous flaps are used [19].

One of the strengths was being able to have received and cared for our patient with a plastic surgery team in a tertiary hospital; unfortunately, these cases could present later in areas where there is not necessarily access to a team to perform this type of intervention. Therefore, we consider it important that this approach be disseminated, which may be useful as an option for other colleagues with similar cases.

\section{Patient perspective}

The presence of lesions of the LC type causes a notable deterioration in the quality of life, especially due to its location (gluteal region), for which the patient refers to the follow-up visits having relieved not only a physical discomfort but also a favorable impact on their quality of life. There is now more comfort to sit, walk, and play. In the words of our patient, living with pain is not life.

\section{Conclusions}

The case presented is about an unusual presentation of circumscribed lymphangioma in the right gluteal region. Despite the existence of multiple approach options today, definitive treatment with surgical removal is necessary, both of them to improve the cosmetic appearance and to prevent associated complications. It is suggested that, as a routine element, histopathological and imaging diagnostic tools (CT and MR) be used, in order to increase therapeutic success, as well as decrease the risk of relapses.

\section{Abbreviations \\ LC: Lymphangioma circumscriptum; ASIS: Anterior superior iliac spine; \\ TFL: Tensor fasciae latae; CT: Computed tomography}

\section{Acknowledgements}

We thank the Hospital "Dr. Valentín Gomez Farías" of the Institute of Social Security at the Service of State Workers, for providing us with the facilities to present this successful experience. We also appreciate the participation of Dr. Patricia Solis for the diagnostic update.

\section{Authors' contributions}

Responsible for identifying and documenting the pathology. Patient followup, RGFA; head of the surgical team, VSJL; surgical and anesthetic strategic planning team, GSJ, RAE, BCP, DHE, JPK, MMK, RMJ, and FRDA; assistant surgeon, RGFA; methodological and statistical manager, TSQL. All authors have read and approved the final manuscript.

\section{Funding}

We declare that we do not receive financing from any institution or external source and that there are no conflicts of interest.

\section{Availability of data and materials}

We are in the best disposition to provide all the documentation that is requested in case it is required by the editorial committee. All the original data and sources will always be available to anyone who wants to consult them.

\section{Declarations}

Ethics approval and consent to participate

The authors declare that all the processes were carried out in accordance with the national bioethical codes and laws and international treaties. The authors declare that they have the autograph consent of the minor's parents to receive this intervention.

\section{Consent for publication}

The authors agree that this article is published and distributed on the platforms of this journal. The authors declare that they have the autograph consent of the minor's parents for the publication of the information generated from here.

\section{Competing interests}

The authors declare that they have no competing interests.

\section{Author details}

${ }^{1}$ Regional "Dr. Valentín Gómez Farias". Guadalajara, Instituto De Seguridad Y Servicios Sociales de los Trabajadores del Estado, Hospital, Av. Soledad Orozco 203, El Capullo, 45100 Zapopan, Jalisco, México. Universidad Juárez del Estado de Durango, Durango, Mexico.

Received: 27 February 2021 Accepted: 11 September 2021

Published online: 01 December 2021

References

1. Bagrodia N, Defnet AM, Kandel J. Management of lymphatic malformations in children. Curr Opin Pediatr. 2015;27(3):356-63.

2. Kokcu A, Sari S, Kefeli M. Primary vulvar lymphangioma circumscriptum: a case report and review of literature. Journal of Lower Genital Tract Disease. 2015;19(1):e1-5.

3. Méndez E. Linfangioma circunscrito mixto. Presentación de un caso. Rev Mex Ped. 1999;66(3):104-7.

4. Perkins JA, Manning SC, Tempero RM, et al. Lymphatic malformations: review of current treatment. Otolaryngol Head Neck Surg. 2010;142(6):795803.

5. Jamal N, Ahmed S, Miller T, et al. Doxycycline sclerotherapy for pediatric head and neck macrocystic lymphatic malformations: a case series and review of the literature. Int J Pediatr Otorhinolaryngol. 2012;76(8):1127-31.

6. Schoinohoriti OK, Theologie-Lygidakis N, Tzerbos F, latrou I. Lymphatic malformations in children and adolescents. J Craniofac Surg. 2012;23: 1744-7.

7. Puig S, Casati B, Staudenherz A, Paya K. Vascular low-flow malformations in children: current concepts for classification, diagnosis and therapy. Eur J Radiol. 2005;53:35-45.

8. Waner M. O. TM. Multidisciplinary approach to the management of lymphatic malformations of the head and neck. Otolaryngol Clin N Am. 2018;51(1):159-72.

9. Gorur K, Polat G, Ozcan C, et al. The role of apoptosis in traumatic versus nontraumatic nasal septal cartilage. Plast Reconstr Surg. 2007;119(6):1773-6.

10. Demirag M, Adin S. A giant cervical lymphangioma. J Craniofacial Surg. 2019;30(3):e275-3.

11. Akhavan S, Agah J, Nili F. Congenital lymphangioma circumscriptum of vulva presenting as multiple giant mass lesions: a case report and literature review. J Obstet Gynaecol Res. 2018;44(5):978-82.

12. Kulungowski A, Patel M. Seminars in pediatric surgery. Semin Pediatr Surg. 2020:27(2). 
13. Mathes SJ, Nahai F. Reconstructive surgery. Principles, Anatomy \& Technique. Vol 2. Churchill Livingstone. 1997.

14. Wei FC, Mardini S. Flaps and reconstructive surgery. 1a ed. China: Elsevier; 2009.

15. Aranguez M, Palmer P, Mediero I, Ollero J. Aspectos Clínicos y Morfológicos de los linfangiomas infantiles: Revisión de 145 casos. An Esp Pediatr. 1996; 45:25-8.

16. Avhad G, Jerajani H. Lymphangioma circumscriptum of the male genitalia. Indian Dermatol Online Jour. 2016;7(1):68-9.

17. Kudur M, Hulmani M. Extensive and invasive lymphangioma circumscriptum in a young female: a rare case report and review of the literature. Indian Dermatol Online J. 2013;4(3):199.

18. Moshe L, Lehavit A, Dan BA, Eyal R, Eyal K, Michael D. Treatment of lymphangioma circumscriptum with combined radiofrequency current and $900 \mathrm{~nm}$ diode laser. Dermatol Surg. 2006:32:790-4.

19. Margaride L, Soler S, Orozco G. Colgajos de fascia lata en la cirugía reconstructiva de la pared abdominal inferior. Rev de Cir Infantil. 1994;3: 129131.

\section{Publisher's Note}

Springer Nature remains neutral with regard to jurisdictional claims in published maps and institutional affiliations.

\section{Submit your manuscript to a SpringerOpen ${ }^{\circ}$ journal and benefit from:}

- Convenient online submission

- Rigorous peer review

- Open access: articles freely available online

- High visibility within the field

- Retaining the copyright to your article

Submit your next manuscript at $\boldsymbol{\nabla}$ springeropen.com 